\title{
Meditation training as adjunct therapy in the management of Crohn's disease - a pilot study
}

\author{
NB HERSHFIELD, MD, FRCPC, W KUBRYN, MSW, LR SUTHERLAND, MD, FRCPC
}

NB HERSHFIELD, W KUBRYN, LR SUTHERLAND. Meditation training as adjunct therapy in the management of Crohn's disease - a pilot study. Can J Gastroenterol 1993;7(8):613-615. In a preliminary pilot study, the authors examined the effect of a seven-week meditation training program on 12 patients with active Crohn's disease. Nine patients completed the study. Of these nine patients, seven demonstrated a decline in the Crohn's disease activity index (CDAI). In the other two patients, the CDAI rose (Wilcoxon matched pairs signal ranked test, $\mathrm{P}<0.05)$. No significant changes in serum orosomucoid were demonstrated. Based on these preliminary findings, the authors think a control study is warranted, and are carrying this out.

Key Words: Crohn's disease, Meditation, Serum orosomucoid

\section{Formation en méditation comme traitement d'appoint dans le traitement de la maladie de Crohn - étude pilote}

RÉSUMÉ : Dans une étude pilote préliminaire, les auteurs ont examiné l'effet d'un programme de formation en méditation d'une durée de sept semaines chez 12 patients présentant une maladie de Crohn active. Neuf patients ont terminé l'étude. De ces neuf patients, sept ont montré un déclin de l'indice d'activité de la maladie de Crohn. Chez deux autres patients, l'indice s'est élevé (épreuve de Wilcoxon, $\mathrm{P}<0,05)$. Aucune modification significative n'a été observée dans l'orosomucoïde sérique. Sur la base de ces résultats préliminaires, les auteurs croient qu'une étude de contrôle est nécessaire et ils s'en chargent.

T HE MANAGEMENT OF CROHN'S disease $(\mathrm{CD})$ has altered little since the original description in 1933. The mainstays of therapy are a combination of immune suppression, nutritional supplements, ablative surgery and emotional support. The recurrence rate is high $(1,2)$, and although consid- erable research is being done, the treatment of the disease is still unsatisfactory because of the lack of a cure.

In recent years, attempts have been made to determine if relaxation techniques can alter the human response to disease. A new term has been introduced: 'psychoneuroimmunology'. This

Departments of Medicine and Social Work, Foothills Hospital at the University of Calgary, Calgary, Alberta

Correspondence and reprints: Dr NB Hershfield, Foothills Hospital, 1403-29 Street NW, Calgary, Alberta T2N 2T9. Telephone (403) 283-6613, Fax (403) 270-7722

Received for publication October 28, 1992. Accepted April 20, 1993

discipline suggests with some preliminary evidence $(3,4)$ that the immune system is linked intimately to the central nervous system, and that meditation and similar techniques can alter physiological responses and pathological states, and can result in improvement in diseases such as hypertension and cancer. There is suggestive evidence that some of these claims are substantiated (5-7), although there is little evidence that alterations in immune function are responsible for this improvement.

We wished to examine the possibility that these methods, based on the 'psychoimmunological hypothesis' has a role to play in the treatment of $\mathrm{CD}$.

We performed a very preliminary pilot study to determine the practicality of meditation techniques in the management of 12 patients with $C D$.

\section{PATIENTS AND METHODS}

This project was approved by the Conjoint Ethics Committee of the University of Calgary. Twelve patients recruited from one of the author's practice and from the Calgary chapter of the Canadian Foundation for Ileitis and Colitis were enrolled in the pilot study.

All patients had well-documented $\mathrm{CD}$ of the small intestine. The group included eight females and four males. All had clinical evidence of active CD, and of the 12 , seven had prior surgery for complications of the disorder. All had the disease for at least five years. The ages of the patients were between 
TABLE 1

\section{Mediation training program sched- \\ ule}

\section{Week 1}

Introduction

A brief breathing meditation and discussion

\section{Week 2}

Explanation and introduction to 'mindfulness meditation'

\section{Meditation practice}

\section{Week 3}

The power of breathing

Diaphragmatic versus thoracic breathing

Body scan and mindfulness meditation

\section{Week 4}

Chronic pain and meditation

Meditation and rellef of pain

\section{Week 5}

Seeing versus perception

Meditation

\section{Week 6}

Vertical versus horizontal living Participating versus observing Reacting versus responding Mindfulness meditation

\section{Weeks 7 and 8}

Review of all learned techniques and practices, including a 'walking meditation'

Discussion and organization of a follow-up program

20 and 51 years. All were on active therapy: corticosteroids (five patients), corticosteroids and aminosalicylate (three), and aminosalicylate (four).

On entry to the study, all patients underwent a history and complete physical examination. The CD activity index (CDAI) was determined at the beginning and the end of the study period. Serum orosomucoid was measured at zero, two, four and eight weeks.

\section{MEDITATION TRAINING}

Many patients with chronic illnesses are told, at some point, that they must learn to live with their chronic illness. This study was designed to observe if patients can be taught by meditation techniques to cope better with their disease and to determine if any changes in clinical status could be measured at the end of the process.

The program consisted of eight

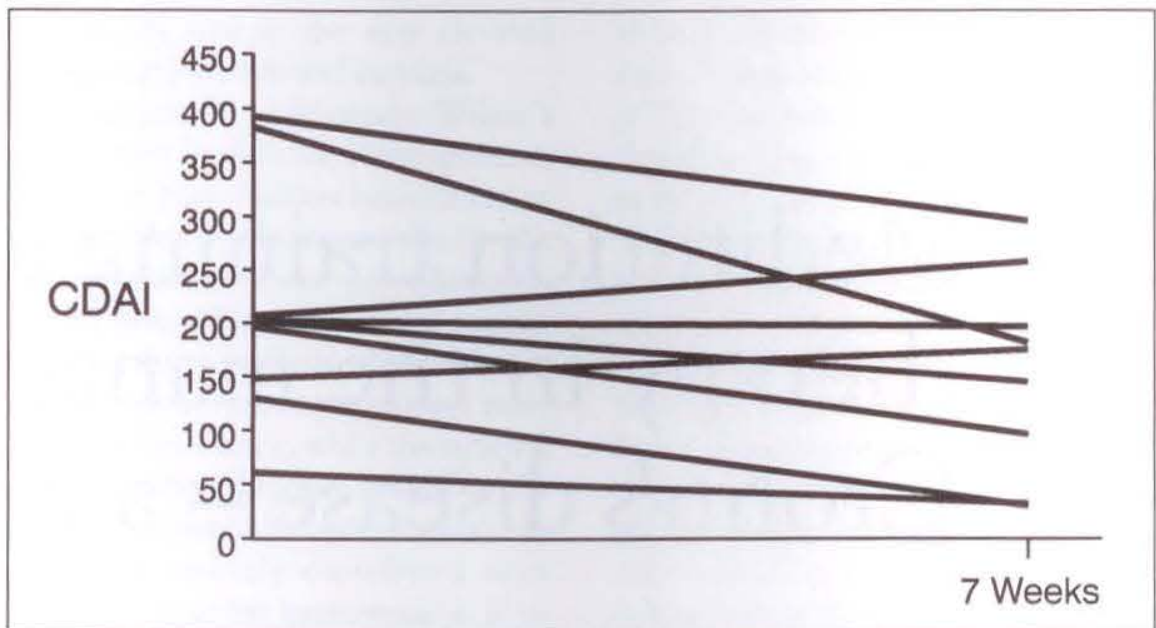

Figure 1) Crohn's disease activity index (CDAI) at entry and at study conclusion. Nine patients completed the study, with seven demonstrating declines in CDAI

meetings. The first seven meetings were held weekly for seven consecutive weeks for two evening hours. The final meeting was a full-day session on a Saturday. The final meeting was held to plan future meetings, and to reinforce the ideas of meditation and the necessity of constant practice in the future.

Each of the first six sessions included theoretical information and discussion. A review of the patient's progress and meditation filled the rest of the time. The patients were asked to practise meditation daily on their own for 20 mins. The trainer observed that all members of the group moved very quickly from being relatively independent to dependency and, near the completion of the sessions, to the recognition of the need to be independent again. A supportive environment was clearly established immediately. The program is outlined in Table 1.

\section{RESULTS}

No changes occurred in the physical examination in those patients that completed the study. As this was a pilot study, extensive statistical examination of the data was not performed. Because the authors could not be sure the sample was normally distributed, a nonparametric test, the Wilcoxon matched pairs signed ranks (8), was performed on those patients who completed the study. This test compares entry CDAI with final CDAI. In seven patients, the final CDAI was less than the entry
CDAI; in the remainder (two patients), the final CDAI was greater than entry CDAI (Figure 1) $(\mathrm{P}<0.05)$. Analysis of the subcomponents of the CDAI was not performed because of the small sample size. Serum orosomucoid levels did not alter significantly.

\section{DISCUSSION}

The magnitude of the impact of inflammatory bowel disease (IBD) in society has been extensively investigated, and is a significant determinant of illness in a large number of patients (9). It has been documented that some of these victims have been unable to sustain a normal lifestyle, occupation or activity because of frequent interruptions due to ill health, hospitalization, surgery and the effects thereof.

The treatment of IBD is fairly straightforward. Corticosteroids and other immunosuppressive drugs are used, as well as aminosalicylates and other immune-modulating drugs. Although remissions are possible, most, if not all, patients usually require some form of ablative surgery. However, there is no guarantee that the whole cycle will not be repeated at another time. Since no cause has as yet been discovered, it is not surprising that no sure remedy is available.

There is no proof that emotional stress plays a role in causing $\mathrm{CD}$, but most physicians and some patients feel the disorder, because of its dismal prognosis and disfigứring effects (from ster- 
oids and surgery), causes considerable distress. Lives of the sufferers are frequently severely altered by the seemingly never-ending problems, resulting in considerable changes in a hitherto balanced life. Some studies have demonstrated that these patients have a higher incidence of drug addiction, divorce, suicide and depression (10).

There have been other previous studies of the psychological treatment for IBD. In one experiment, Schwarz and Blanchard (11) analyzed the results of a multi-treatment package in a randomized clinical trial in patients with ulcerative colitis and CD. It was concluded that the control group had fewer symptoms than the treated group, although the authors stated that the treated patients perceived that they were better able to cope with their symptoms at the end of the study period. Groen and Bastiens (12) treated 29 patients with ulcerative colitis with psychotherapy alone. They concluded that in this uncontrolled study, the method was highly effective. No clinical details were given. Joachim et al

ACKNOWLEDGEMENTS: Funded in part by the Foothills Hospital Foundation.

\section{REFERENCES}

1. Goligher JC. The outcome of incisional operations for primary and recurrent Crohn's disease of the large intestine. Surg Gynecol Obstet 1979;148:1-8.

2. Korsen R, Serch-Hansen A, Thoreson BA, et al. Crohn's disease: Longterm results of surgical treatment. Scand J Gastroenterol 1981;16:57-64.

3. Glaser R, Kielcot JK. Stress-related impairments in cellular immunity. Psych Res 1985;16:233-89.

4. Rossi EL. The psychobiology of
(13) used deep breathing, massage and 'imagery' in 15 patients with IBD (type not specified). Improvement in coping skills was claimed by the patients. Milne and co-workers (14) treated 80 patients with stress management techniques in an uncontrolled experiment and noted some improvement, although details of the diseases were not mentioned. CDAI assessment was not used.

In our uncontrolled study, it is obvious that no definitive conclusion can be made. Although CDAI improved in seven of nine patients who completed the study, this may have been due to a number of unrelated factors, such as the so-called 'group effect', or that these particular patients were impressed that a new form of 'treatment' was being tried. In addition, the effect of almost constant attention by trained, interested and empathetic caregivers may have made coping with the disorder much easier. In our discussions with the patients after the conclusion of the study, some noted that these skills improved. There were no differences in the biochemical values or orosomucoid

mind-body healing. New York: WW Norton \& Co Inc, 1986.

5. Klein KB, Spiegel D. Modulation of gastric secretion by hypnosis.

Gastroenterology 1989;96:1383-7.

6. Banks W. Hypnotic suggestion for the control of bleeding in the angiography suite. Erickson Monographs 1985;1:76-88.

7. Benson H. Beyond the Relaxation Response. New York: Berkley Books, 1984.

8. Sandler RS, Jordan MC, Kupper LL, et al. Development of a Crohn's disease activity index. Gastroenterology 1976;70:439-41.

9. Norusis MJ. Spss PC +4.0. Chicago: SPSS Inc, 1990.

10. Kaplan RS, Korelitz BI. Narcotic levels at the beginning and at the end of the study period. Since there is no repeatable 'immune' measurement that is shared by all IBD patients, we have no proof that the improvement in the CDAI was due to improvement in immune function, although it theoretically is possible with the now substantiated connection between the immune system and the central nervous system.

Nevertheless, we think that this line of research is worth pursuing and we are embarking on a further experiment, comparing two groups of patients. One group will undergo meditation training similar to our pilot group and a second group will be taught other methods, such as imagery and visualization, in addition to meditation, and the two groups will then be compared.

\section{CONCLUSION}

A pilot study using meditative techniques was performed on nine patients with $\mathrm{CD}$. The results are encouraging enough to embark on a more detailed experiment, using two groups to determine if these methods are useful.

dependency in inflammatory bowel disease. J Clin Gastroenterol 1988;10:275.

11. Schwarz SP, Blanchard EB. Evaluation of a psychological treatment for inflammatory bowel disease.

Behavioral Res Ther 1991;29:166-77.

12. Groen J, Bastiens J. Psychotherapy and ulcerative colitis. Gastroenterology 1951;18:344-52.

13. Joachim $G$. The effects of two stress management techniques on feelings of well being in patients with inflammatory bowel disease. Nurs Pap 1983;15:15-8.

14. Milne B, Joachim G, Niedhardt J. A stress management program for inflammatory bowel disease. J Advan Nurs 1986;11:561-7. 


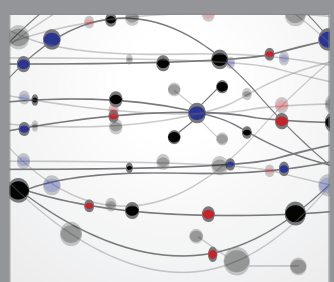

The Scientific World Journal
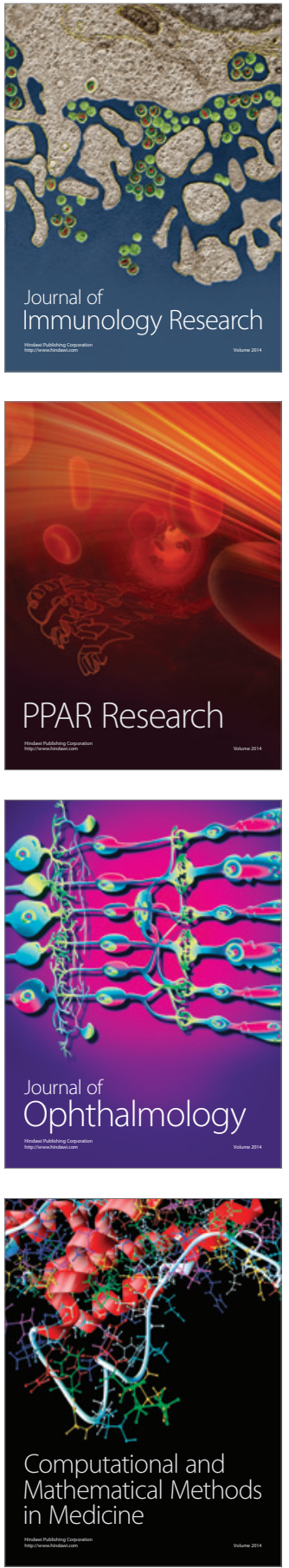

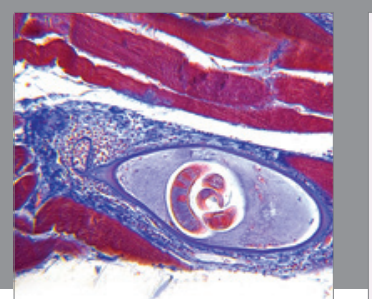

Gastroenterology Research and Practice

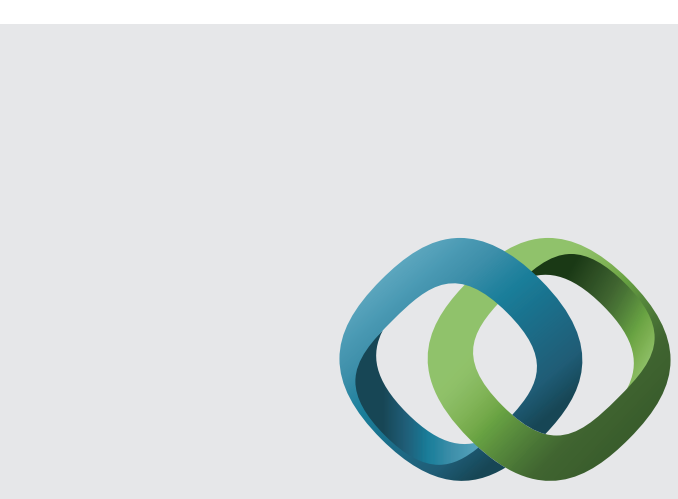

\section{Hindawi}

Submit your manuscripts at

http://www.hindawi.com
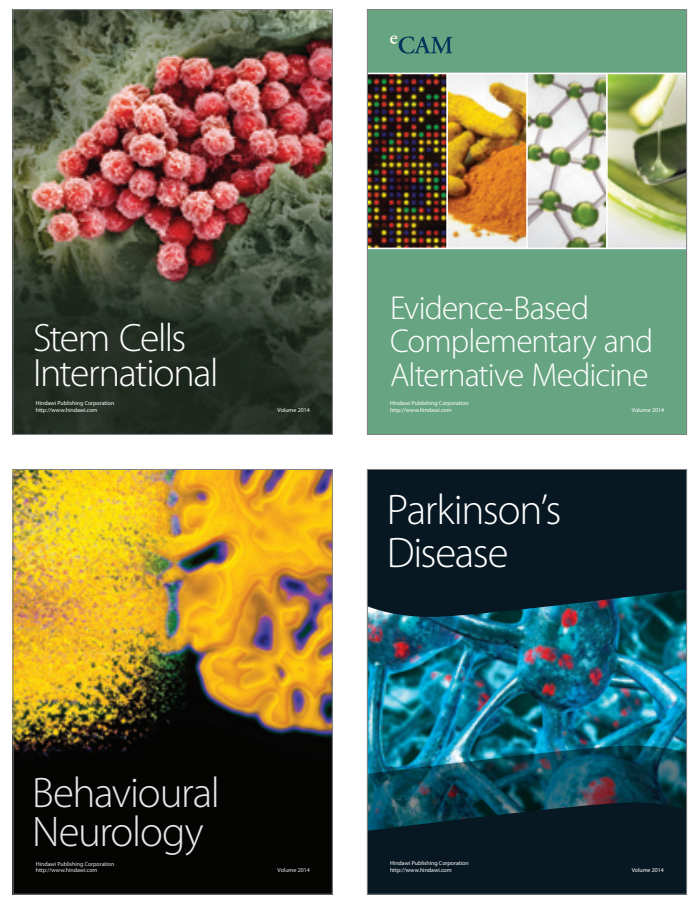
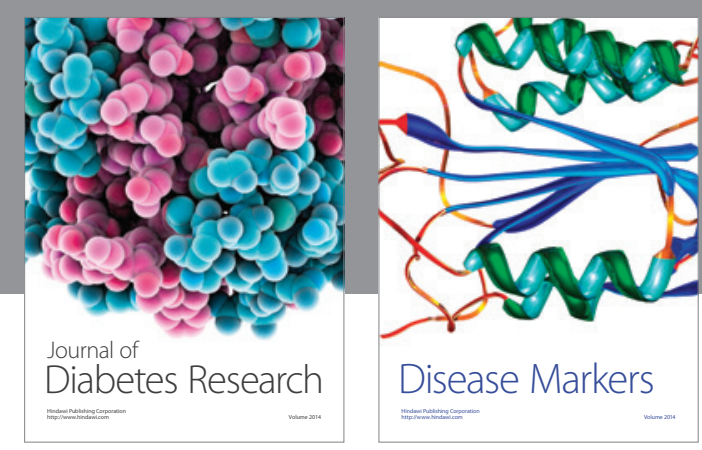

Disease Markers
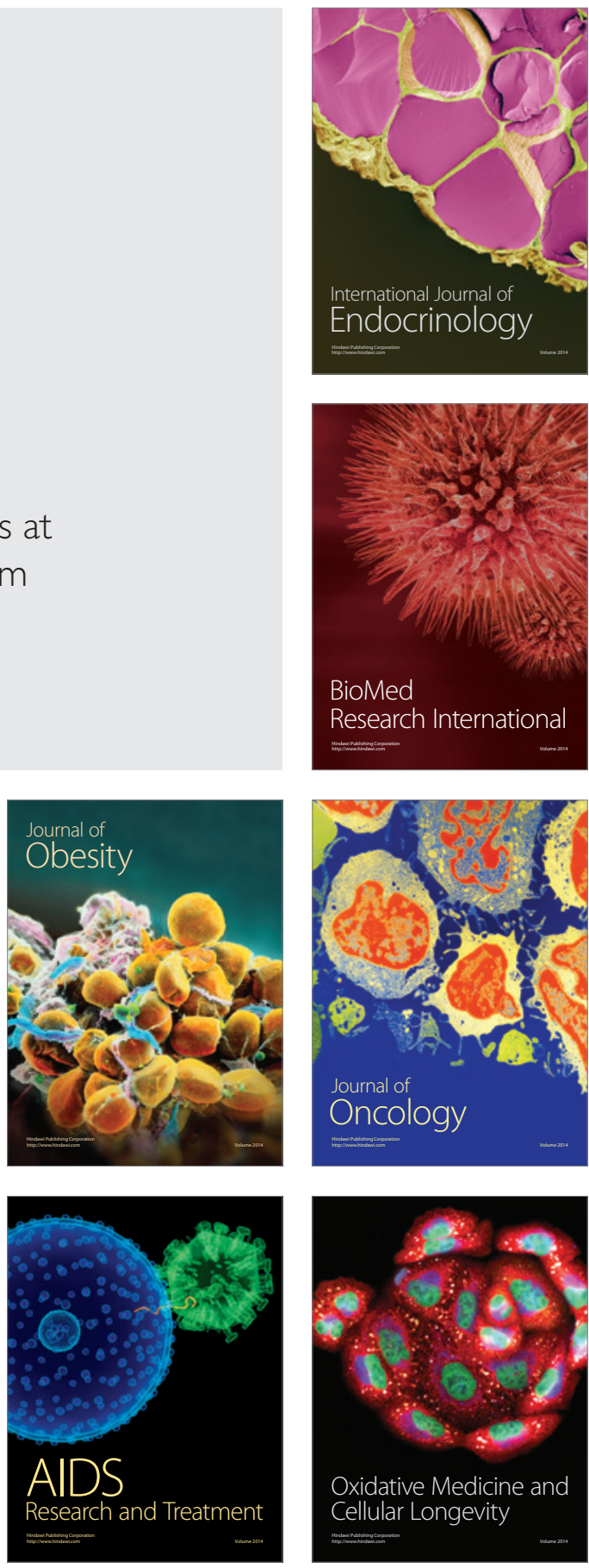